\title{
State of Tourism Development in Nepal with Special Focus on Changing Purpose of Visit
}

\author{
Suman Kharel* \\ Lecturer, Central Department of Rural Development, Tribhuvan University, Kathmandu, Nepal
}

*Corresponding Author: Suman Kharel, Lecturer, Central Department of Rural Development, Tribhuvan University, Kathmandu, Nepal

\begin{abstract}
Nepal has a wide range of tourism resources and attractions. The country ranges from about 60 meters elevation to the world's highest mountain peak. It has the Himalayan Mountain range, different types of climate, rich biodiversity and beautiful landscapes. The world's major highest mountain peaks, mountain ranges, world famous trekking destinations and cultural diversity, historical landmarks and natural heritage and professional hospitality. With some exception, the volume of tourist has been gradually increasing and recently it has reached to over one million. However, tourism development is still in its early stage as the volume of tourist is still low and it is further characterized with seasonality with short period of stay. Based on the secondary data, this paper examines the changing size and the trend of tourist flow to Nepal. The findings show an increasing trend of tourists with gradual shifting geographical areas of origin of tourist. Furthermore, a shift has also observed in the purpose of the visit of tourists.
\end{abstract}

Keywords: Nepal, changing trend, trekking, country of origin, seasonality, visiting purpose

\section{INTRODUCTION}

Tourism is a service based industry. United Nations World Tourism Organization (UNWTO) defines tourism as 'a social, cultural and economic phenomenon which entails the movement of people to countries or places outside their usual environment for personal or business/ professional purposes. These people are called visitors and tourism has to do with their activities, some of which involve tourism expenditure", (http://cf.cdn.unwto.org/sites/all/files/Glossary+of+terms.pdf accessed on March 17, 2019). It has further specified that such travels should be outside the usual place of residence for multiple purposes, including leisure and business for the duration exceeding a consecutive year.

Nepal has a short history of tourism. It has started since after the dawn of democracy in 1950s. The systematic tourism development started with successful climbing of Annapurna I on 3 June 1950 by Maurice Herzog and Louis Lachenal of France and especially after the climbing of Mt. Everest by Tenzing Norgay Sherpa of Nepal and Sir Edmund Hillary on 29 May 1953 (Shrestha and Shrestha, 2012). However, there is history of travelling some great people to and from Nepal in ancient time. A few of such historical visits include the visit of Manjushree to Kathmandu Valley (Bhandari 2030 BS:17), Ashok's visit to the birthplace of Lord Buddha Lumbini, Chinese traveler Huien-Tsang to Nepal in 643 A. D. (Sharma, 2033) and Captain Kirk Patrick's visit of 1792.

In the early phase of tourism development, it had highlighted the sacredness of the Himalayas, and beautiful mountains and the cultural heritage of the country. The early literature on tourism focused to mountain ranges and mountain peaks were the center of attractions for which the great saint, monk and the nobilities from both north and south visited Nepal. With the expansion of colonialism, western traveler visited Nepal and introduced the country to the western world (Bhandari, 2030 BS). However, tourism was considered a means of livelihood and its importance in the national economy during the 1980s and later. Furthermore, it was linked to environment and development of the country (Baskota and Sharma, 1995; Stevens, 1993a; Stevens, 1997; Subedi and Chapagain, 2011; Poudel, 1998; Ives, 2006; Chapagain, 2017). Tourism is certainly one of the major sectors of employment and income generation in the country and has its comparative advantages that can be divided into three groups: sceneries and natural beauty, trekking and adventure, and pilgrimage, art and sculptures which are unique in Nepal (Sharma and Pyakurel, 2012). 
Although there are numerous literatures on different aspects of tourism in Nepal, most of those works discuss specific areas. However, these research works fairly make a comprehensive analysis of tourism development and its emerging trends in Nepal in a broader spectrum. This paper aims to assess general patterns, trends of tourism industry in contexts of origin and specific purposes of visit to Nepal, using secondary data.

\section{METHODS AND MATERIALS}

This paper is based on the secondary data published by Ministry of Culture, Tourism and Civil Aviation (MCTCA) of Nepal. The tourism statistics and various publications of MCTCA, and Nepal Tourism Board are the major sources of tourist data from 1964 to 2018 that has been collected and analyzed with supports of Microsoft Excel. Tourism data of 2018 has been extracted from Nepal Tourism Board (see https://trade.welcomenepal.com/downloads-cat/nepal-tourism-statistics/ access on March 11 2019). In order to reflect the changing trend of tourist volume and trend, seasonality, nationality of tourists, and visiting purposes, the secondary data available have been tabulated under various themes: tourism volume, trend, purpose and nationality. Furthermore, various publications, such as research papers, books, and reports are used as the sources of information.

\section{RESULTS AND DISCUSSION}

\subsection{Volume and Trend of Tourist Arrival}

The number of tourists visiting to Nepal has immensely been increasing over the time. The available data 1964 to 2018 indicate that the total number of visitors was about 9400 in 1964 that has reached to $1,173,072$ in 2018 . The volume of tourist has steadily increased until 2000. However, it has decreased thereafter until 2006. The temporary decline in tourists' arrival was mainly due to the internal conflict in Nepal. In 2006, the peace accord was signed and tourism sector was again revived and the number of tourists substantially declined. However, the number of visitors again decreased due to the April 2015 earthquakes in Nepal. The 7.8 Richter scale Nepal earthquakes hit the major tourist season of summer while adversely affecting the other season, ranging from September to October. The number of tourists was again increased from 2016 and reached to over one million by 2018 (Table1, Figure 1).

Table1: Volume and trend of tourist arrival, 1965-2018

\begin{tabular}{|l|l|l|l|}
\hline Year & \multicolumn{1}{|c|}{ Total number of tourist arrival } & \multicolumn{1}{c|}{ Year } & \multicolumn{1}{c|}{ Total number of tourist arrival } \\
\hline 1965 & 9,388 & 2010 & 602,867 \\
\hline 1970 & 45,970 & 2011 & 736,215 \\
\hline 1975 & 92,440 & 2012 & 803,092 \\
\hline 1980 & 162,897 & 2013 & 797,616 \\
\hline 1985 & 180,989 & 2014 & 790118 \\
\hline 1990 & 254,885 & 2015 & 538970 \\
\hline 1995 & 363,395 & 2016 & 753002 \\
\hline 2000 & 463,646 & 2017 & 940218 \\
\hline 2005 & 375,398 & 2018 & $1,173,072$ \\
\hline
\end{tabular}

Source: MCTCA 2018

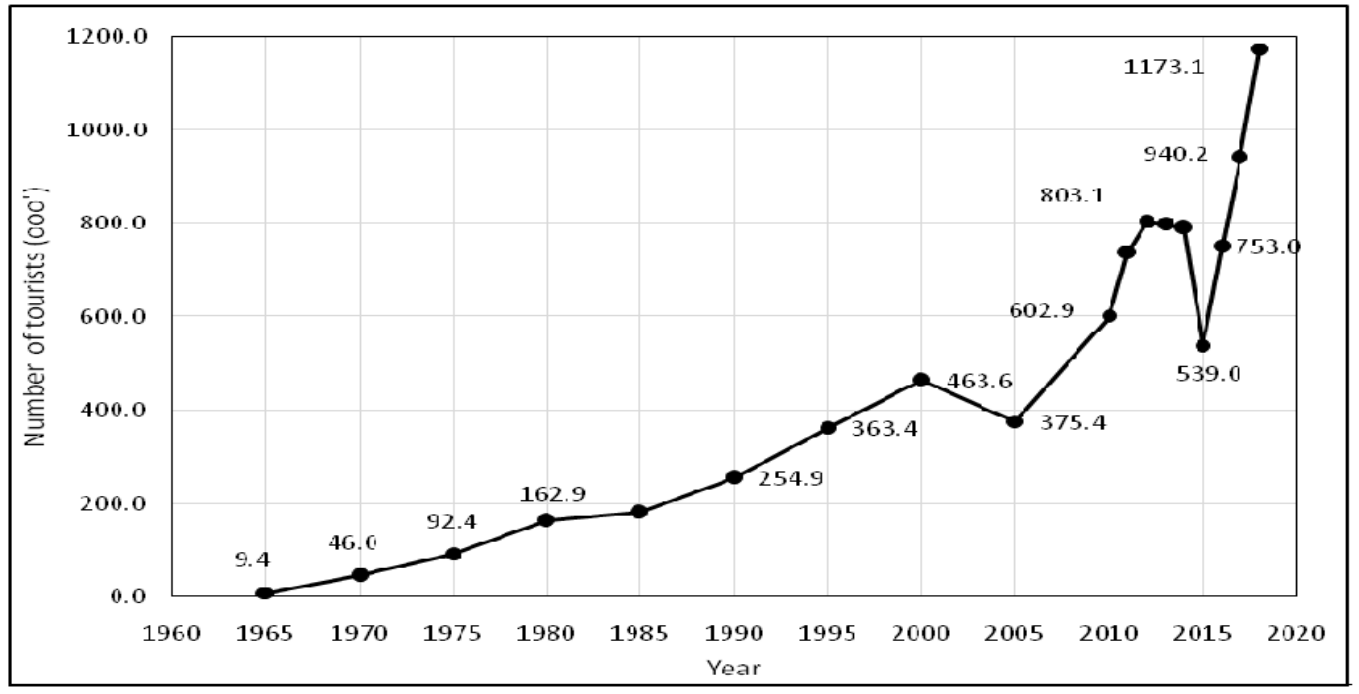

Figure1: Volume and trend of tourist arrival in Nepal, 1965-2018 
After the devastating Nepal earthquakes, the unofficial Indian embargo severely affected Nepal's economy as Nepal's more than 80 percent trade is with India. Nepal depends upon India for major essential supplies such as food stuff, medicine, cooking gas, and other petroleum products and such supplies were unofficially blocked immediately after the declaration of the new constitution of Nepal in September 2015. The blockade paralyzed the normal life and directly affected to the tourism industry. It also affected the Indian tourists to Nepal.

\subsection{Number of Tourists by the Country of Origin}

Although tourism is a global phenomenon, there are only a few countries of origin of tourists to Nepal. From the beginning, only a few countries, such as India, UK, USA, and Japan remain the major source areas of tourists to Nepal. Because of open borders and similar cultural background, a large number of Indian tourists visit Nepali. Indian has shared about 25 percent of the total tourists to Nepal in 2003 that has been decreased to 20 percent in 2010 and about 14 percent in 2015 and 17 percent in 2017. The second major source areas of tourist include Europe, America, Japan and Australia until 2005. However, the trend has gradually changed and a few countries particularly China and Shree Lanka enlisted as major source area of tourist by 2005. The percentage of Indian, European, and Japanese tourists has started to decline. Furthermore, being the birth place of Lord Buddha, tourists from South Asian and East Asian countries particularly Shree Lanka, Thailand, Myanmar and South Korea have been increased. The percentage of Indian tourist is still high but it is in a decreasing order but the percentage of Chinese tourist has been consistently increasing and remains the second largest after 2005 (Table 2, Figure 2).

Table2: Percentage of tourist by country

\begin{tabular}{|l|l|l|l|l|l|}
\hline \multicolumn{1}{|c|}{ Nationality } & \multicolumn{5}{|c|}{ Percent by Year } \\
\cline { 2 - 6 } & 2005 & 2010 & 2015 & 2016 & 2017 \\
\hline Germany & 3.8 & 3.7 & 2.3 & 3.2 & 3.2 \\
\hline France & 3.8 & 4.1 & 3 & 2.3 & 2.8 \\
\hline Spain & 2.4 & 2.3 & 0.8 & 1.6 & 1.7 \\
\hline U.K. & 6.7 & 5.8 & 3.8 & 6.2 & 5.4 \\
\hline India & 25.5 & 20.1 & 13.9 & 15.7 & 17.1 \\
\hline Sri Lanka & 5 & 7.6 & 8.2 & 7.6 & 4.8 \\
\hline Thailand & & & 5.7 & 3.6 & 4.2 \\
\hline South Korea & & & 3.4 & 3.3 & 3.6 \\
\hline Myanmar & & & & 3.4 & 3.3 \\
\hline China & 6 & 7.7 & 12.4 & 13.8 & 11.1 \\
\hline Japan & 4.9 & 3.9 & 2.7 & 3.1 & 2.9 \\
\hline Australia & 1.9 & 2.7 & 3.5 & 3.4 & 3.6 \\
\hline U.S.A. & 4.9 & 6 & 10 & 7.1 & 8.4 \\
\hline Total number of tourist & 375,398 & 602,867 & 538,970 & 753,002 & 940,218 \\
\hline
\end{tabular}

Source: MCTCA, 2018

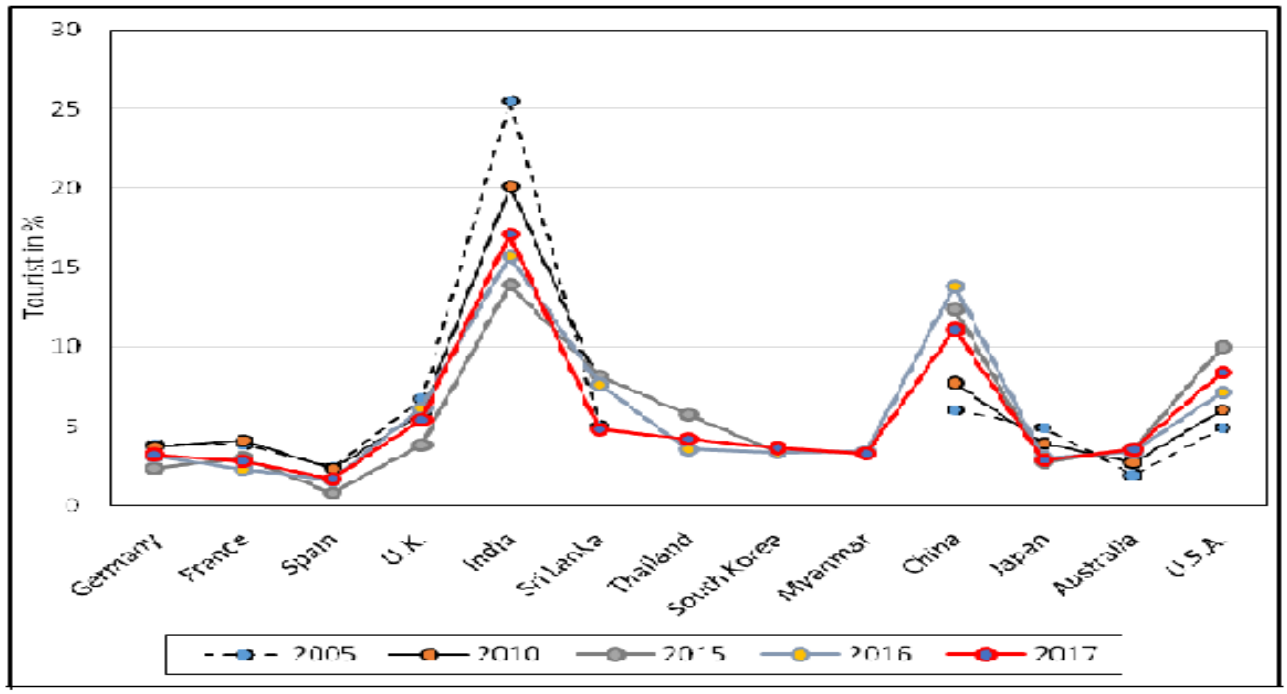

Figure2: Percentage of tourist by country of origin, 2005-2017.

Source: Based on Table 2 


\subsection{Purpose of Visit}

People primarily travel for enjoyment and pleasure. However, there are six major purposes of tourists visit to Nepal. These are holidays/pleasure, pilgrimage, trekking/mountaineering, business, official, and seminar/conference. Out of the six major purposes, holiday/pleasure and trekking/mountaineering are the two major purposes of visit. These two purposes cover about 75 percent of the total tourists visiting to Nepal. Trekking /mountaineering has been one of the major purposes of visit for a long time. It is the major purpose that Nepal is famous for different types of trekking, adventure tourism and mountaineering to world highest peaks. Nepal has trekking destinations such as Annapurna Trekking Circuit (ATC), Everest trekking, Langtang, upper Mustang, Dolpo and so on which are established as the brand in the world (Table 3).

Table3: purpose of visit of tourist

\begin{tabular}{|l|l|l|l|l|l|l|l|}
\hline \multirow{2}{*}{ Year } & \multicolumn{7}{|c|}{ Purposes of visit } \\
\cline { 2 - 8 } & Holiday pleasure & Pilgrimage & Trekking/Mount. & Business & Official & Seminar/conf. & Other \\
\hline 2005 & 42.7 & 12.7 & 16.4 & 5.9 & 4.5 & 0.0 & 17.9 \\
\hline 2010 & 43.8 & 16.8 & 11.6 & 3.5 & 4.4 & 1.6 & 18.2 \\
\hline 2015 & 71.6 & 2.8 & 1.7 & 3.9 & 4.0 & 1.7 & 14.4 \\
\hline 2017 & 70.0 & 15.0 & 8.0 & & & & 7.0 \\
\hline
\end{tabular}

Source: Calculated from MCTCA, 2016 and 2018

In terms of purpose of visit, it has been observed a major shift that the percent of visitors from trekking/mountaineering has been decreasing and the percentage of pilgrimage has been increasing. This shift is basically due to the growing interest of both Buddhist population of South and South Asian countries including China who visit different sacred places related to Lord Buddha and the Indian tourist to such places including to Pashupatinath, Muktinath and other places in Nepal. In 2000 , there was only about 3 percent tourist for the purpose of pilgrimage that has been increased to about 12 percent in 2010, 17 percent in 2015 and 15 percent in 2017 (Table 3, Figure 3).

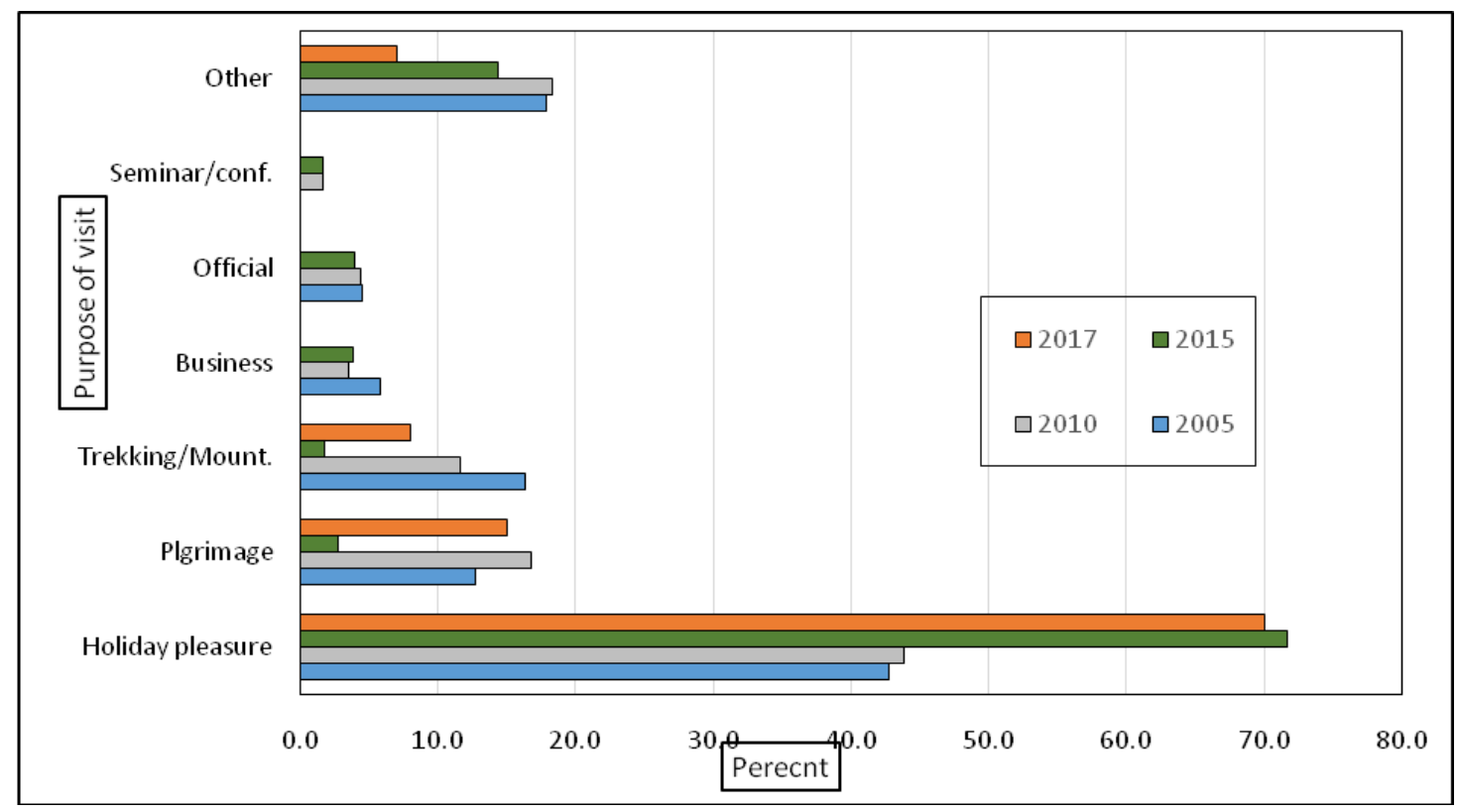

\subsection{Seasonal Trend}

Tourism in Nepal is very seasonal. It has observed two major tourist seasons. These are February April, and September - November. These two seasons have become significant in the persistently observed since long back. The last two decades data indicate that February-April season shares about 30 percent of the total tourists while September- November season shares about 35 percent of the total annual tourists to Nepal. Furthermore, it has also observed the concentration of visitors in particular months. For example, the highest percent of tourists visit to Nepal in March and October. The statistics unfold that about 11 percent of total annual visitors come in March and 16 percent in the month of September (Figure 2). 


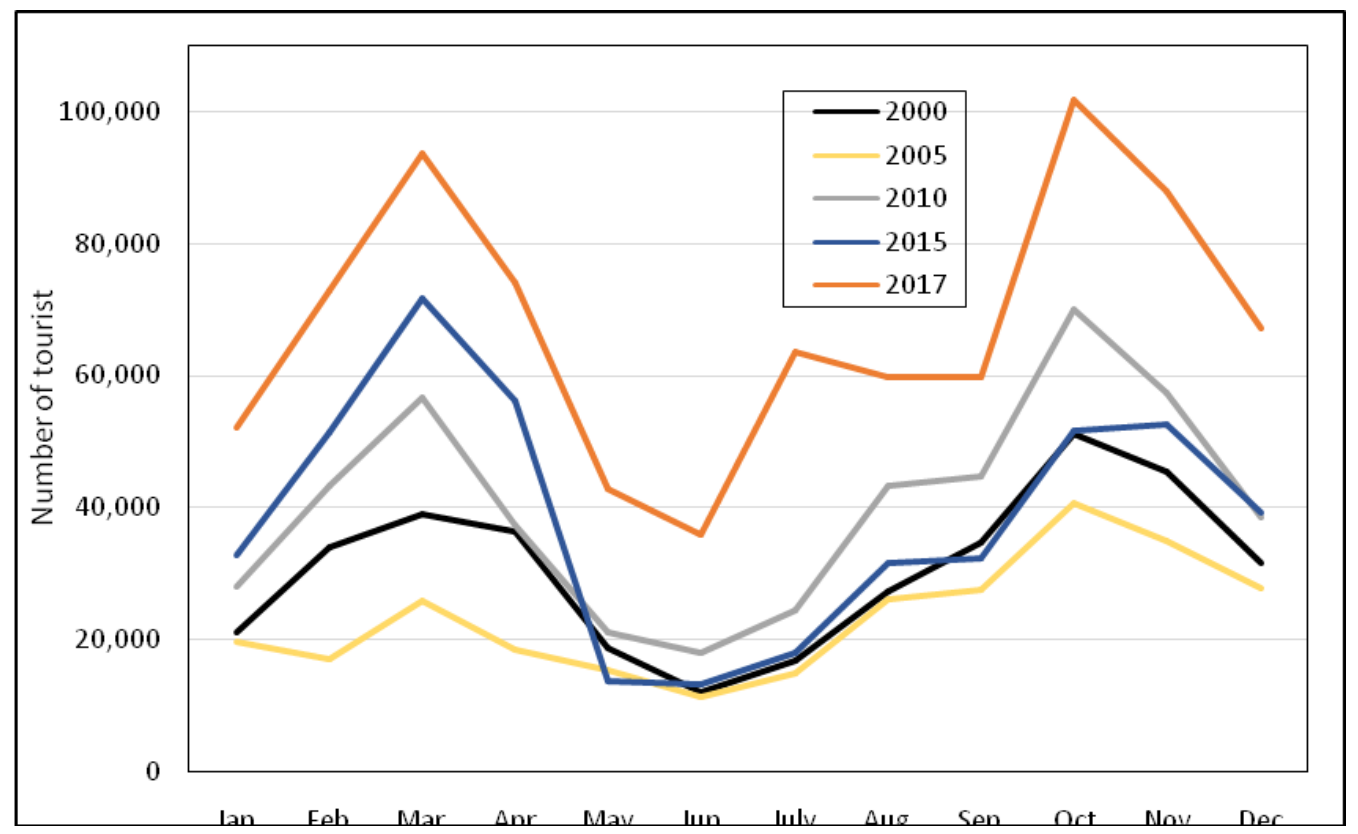

Figure2: Trend of tourist (other than Indian) arrival by month

There are some reasons after the concentration of tourists in these two seasons. These two seasons are pleasant in terms of weather and cultural heritage. Both seasons are neither hot nor cold. The major attraction of the later season, September- November, is that the major festivals of Nepal, such as Dashain, Tihar, and Chhat take place during this time. Nature become colorful and people celebrate festivals. These natural and cultural attractions are also reflected in the flow pattern of tourists to Nepal (Figure 2).

\section{CONClusion}

Tourism is one of the major resources of Nepal. Numerous tourists visit Nepal for physical diversity, diversity of climate, biodiversity and cultural richness. Despite these attractions, the volumes of tourist have just crossed one million. There are still a few spatial pockets of tourists' origin countries to Nepal. More than two third of the total tourists to Nepal are from India, China, UK, USA, Japan, Srilanka, Myanmar and Thailand. Tourism activities are still concentrated in certain trekking corridors and conservation areas, and to the cultural heritage sites. Tourism is still seasonal activity that about two-third tourists visits in two seasons mainly March- April and October-November.

The major shift in tourism development has appeared over the last two decades that can be pointed out in four types. The first one is that the number of Chinese tourists has abruptly increased from 2.2 in 2003 to 7.7 percent in 2010 and about 14 percent in 2016 and China become the second largest country of tourists to Nepal. Second, the percent of Indian tourist is still at the top but their percentage has been gradually decreasing. Third, the percentage of western European tourists is also gradually decreasing. Forth, the percentage of tourists from the South, and East Asian countries particularly from Srilanka, Thailand, Myanmar and Vietnam has been increasing especially after 2005 (Figure 4) and its seems that the trend will continue in future too. With increasing number of tourists from South and South Asian countries the purpose of visit has also been changing as pilgrimage has become one of the major purposes of visit.

\section{REFERENCES}

[1] Banskota, K., \& Sharma, B. (1995). Mountain tourism in Nepal: An overview. MEI Discussion Paper 95/7. Kathmandu: ICIMOD

[2] Bhandari, D.R. (2030BS), Nepalko Yetihasik Bibechana, Varanasi: Krishna Kumari Devi.

[3] Chapagain, P.S. (2017). "Firewood management practice of hoteliers and non-hoteliers and forest situation in Langtang Valley, Nepal Himalayas." The Geographical Journal, 10: 55-72.

[4] Ives, J. D. (2006). Himalayan perceptions: Environmental changes and the well-being of mountain peoples. Second Edition. Lalitpur: Himalayan Association for the Advancement of Science.

[5] MCTCA. (2011). Nepal Tourism Statistics 2010. Kathmandu: Ministry of Culture, Tourism \& Civil Aviation, GoN. 
[6] MCTCA. (2012). Nepal tourism statistics 2011. Kathmandu: Ministry of Culture, Tourism and Civil Aviation, GoN.

[7] MCTCA. (2013). Nepal tourism statistics 2012. Kathmandu: Ministry of Culture, Tourism and Civil Aviation, GoN.

[8] MCTCA. (2015). Nepal tourism statistics 2014. Kathmandu: Ministry of Culture, Tourism \& Civil Aviation (MCTCA), GoN.

[9] MCTCA. (2016). Nepal tourism statistics 2015. Kathmandu: Ministry of Culture, Tourism and Civil Aviation, GoN.

[10] MCTCA. (2018). Nepal tourism statistics 2017. Kathmandu: Ministry of Culture, Tourism and Civil Aviation, GoN.

[11] Paudel, P.C. (1998). Mountain Tourism and its Socio Economic Impact in Ghandruk VDC, Annapurna Region, Nepal. The Himalayan Review, 29: 37-52

[12] Sharma, B.C. (2033BS), Nepalko Yetihasik Roop Rekha, Varanasi: Krishna Kumari Devi.

[13] Sharma, S.R., \& Pyakurel K. (Eds.) (2012). Nepal 2030: A vision for peaceful and prosperous nation. Kathmandu: NCCR North-South/ Kathmandu University.

[14] Shrestha, H.P \& Shrestha P. (2012). Tourism in Nepal: A Historical Perspective and Present Trend of Development. Himalayan Journal of Sociology \& Anthropology, 5:54-75.

[15] Stevens, S.F. (1993a). Tourism, change, and continuity in the Mount Everest Region, Nepal. Geographical Review, 83 (4): 410-427

[16] Stevens, S.R. (1997) 'Annapurna conservation area: Empowerment, conservation and development in Nepal'. In S. Stevens (Ed) Conservation through cultural survival. Indigenous Peoples and Protected Areas. (Pp. 237-262). Washington, D.C.: Island Press.

[17] Subedi, B.P. \&Chapagain, P.S. (2011). Tourism development in Upper Manang Valley of Annapurna Region. Nepal Tourism and Development Review, 1(1):56-68.

Citation: Suman Kharel. "State of Tourism Development in Nepal with Special Focus on Changing Purpose of Visit". International Journal of Research in Tourism and Hospitality (IJRTH), vol 5, no. 3, 2019, pp. 01-06. doi: http://dx.doi.org/10.20431/2455-0043.0503001.

Copyright: (C) 2019 Authors. This is an open-access article distributed under the terms of the Creative Commons Attribution License, which permits unrestricted use, distribution, and reproduction in any medium, provided the original author and source are credited. 